\title{
Coordination in global $R \& D$ organizations: an examination of the role of subsidiary mandate and modular product architectures in dispersed R\&D organizations
}

\begin{abstract}
International research and development $(R \& D)$ operations require a significant amount of coordination between the headquarters and the subsidiaries in order to integrate the dispersed activities in one final product. This article explores what mechanisms multinational companies (MNCs) use to coordinate their overseas $R \& D$ units. Based on a multiple case study involving nine MNCs with overseas $R \& D$ subsidiaries of varying mandates, we find that $R \& D$ sites with high technology and/or market orientation tend to be coordinated by informal mechanisms while sites with little technology and/or market orientation tend to be coordinated by formal mechanisms. Furthermore, it appears that this relationship is strongly affected by the product's architecture: while rather complex $R \& D$ activities are conducted at the systems level and at sites with high technology orientation, less complex $R \& D$ activities are conducted at the component level at sites with low technology and market orientation. Finally, the findings suggest that modular product architectures have a coordinating effect in global R\&D activities which have the power to lower firms' overall coordination effort. The findings bear important implications for the effective coordination of MNCs' international $R \& D$ subsidiaries.
\end{abstract}

\section{Keywords}

Formal Coordination, Informal Coordination, Hybrid Coordination, Subsidiary mandate, R\&D subsidiaries, Product architecture, Product modularity, Global R\&D, MNCs

\section{Introduction}

An enduring challenge for the contemporary multinational company is to be globally effective while being able to respond to local market requirements (De Meyer and Mizushima, 1989; Martinez and Jarillo, 1991; Nobel and Birkinshaw, 1998). This challenge materializes in the question which products should be developed for the global market and which products necessitate an adaptation to the specific needs of a local market. More recently, the increasing internationalization of $\mathrm{R} \& \mathrm{D}$ has compounded this challenge as competencies and resources have become globally dispersed (Birkinshaw, 1996; Gassmann and von Zedtwitz, 1999). Especially R\&D typically involves a high amount of uncertainty and tacit knowledge which 
corroborates the firm's activities to managing the international R\&D organization (Reger, 2004). This is particularly true for large, diversified firms with a far-flung international R\&D network where the different R\&D sites contribute to the firm's technology and product portfolio. MNCs in this situation are forced to coordinate their dispersed R\&D activities to achieve "integration among different units within an organization" (Martinez and Jarillo, 1989).

With the strong emergence of multinational firms in the 60s and 70s, research on coordination in globally active firms has gained increasing attention. Extant research on coordination in MNCs has predominantly focused on the mechanisms used to coordinate the activities of the firms' subsidiaries in the light of the subsidiary's mandate (Ambos and Schlegelmilch, 2007; Cray, 1984; Martinez and Jarillo, 1991). While it is commonly agreed that coordination mechanisms must be adapted to the specific context in which they are used, there is little understanding about how R\&D activities are coordinated within the MNC, apart from a few exceptions (e.g. Asakawa, 2001; Manolopoulos et al., 2011). Due to the different types of innovation activities ranging from simple re-design to complex technology development, the coordination of $R \& D$ activities is presumably more encompassing than the general subsidiary coordination. This article uses the subsidiary's technology and market orientation as indicators of the subsidiary's $R \& D$ mandate to investigate how coordination mechanisms vary across these different degrees of orientation. Hence, the research question we address is: what are the mechanisms that MNCs use to coordinate their international $R \& D$ subsidiaries and how do they relate to the subsidiary's mandate as determined by their technology and market orientation? This article contributes to extant literature on coordination in multinational firms in at least two ways: first, by explicitly considering the context of $R \& D$, we show what mechanisms global $R \& D$ organizations use to coordinate their dispersed $R \& D$ activities ranging from simple engineering and adaptation activities to complex technology, systems, and architecture development. Second, the article extends coordination literature by highlighting the coordinating power of modular product architectures which may lower the need for formal and informal coordination.

The paper is structured as follows. In the next section we review relevant literature on coordination and the different types of R\&D subsidiaries which exist in multinational firms. Following the research methodology section, we present and discuss the findings of nine case studies of single subsidiaries of MNCs regarding the headquarters' coordination of their different subsidiaries. The article concludes with implications for theory and management practice regarding the effective coordination of international R\&D activities. 


\section{Literature Review}

\subsection{Types of coordination}

\subsubsection{Formal Coordination}

Coordination entails the alignment and integration of value-adding activities which are interdependent but performed by different entities (Child, 1973; Malone and Crowston, 1994; Martinez and Jarillo, 1991; Srikanth and Puranam, 2011; Thompson, 1967). Research on coordination has traditionally distinguished two basic mechanisms, i.e., formal and informal coordination mechanisms (Martinez and Jarillo, 1989; Reger, 1999). Formal mechanisms are embodied in organizational structures and procedures and involve the departmentalization, centralization, formalization, planning, as well as output and behavioral control of dispersed tasks (Martinez and Jarillo, 1989). Typical examples of formal coordination between two departments include routine meetings, routine processes, conference calls, or the exchange of standard documents. As such, formal coordination builds the structural approach to the interrelation between two organizational units. A concept which is often synonymously used for coordination is the concept of control, which can be distinguished in behavioral and output control (Ouchi and Maguire, 1975). Control can be readily exerted when common goals are agreed upon and when means-end relations between the different organizational units are completely understood. The concept of control therefore exhibits strong elements of formal coordination and is henceforth considered a formal mechanism.

\subsubsection{Informal Coordination}

Informal coordination entails activities where two or more partners make substantial contributions of resources and know-how to agreed aims (Archibugi and Iammarino, 1999; Bergek and Bruzelius, 2010). Informal coordination targets at personal attitudes and relations between employees and therefore involves the socialization of employees, the establishment of cross-departmental relations, and informal communication between people and departments (Manolopoulos et al., 2011; Martinez and Jarillo, 1991). Informal communication can be achieved through personal contacts between R\&D people, conferences and seminars or the exchange of scientists (Reger, 2004). Informal coordination through socialization includes, for example, the development of joint goals and strategies, common values and norms, or education and personal development programs (Reger, 2004). Informal coordination is also often achieved through direct collaboration between two or more different entities. This is the case when collaboration is characterized by unstructured, affective relationships and when it is predicated on mutual understanding and a common vision, shared resources, and a joint effort at reaching a common goal (Kahn, 1996). As informal coordination is an intangible approach that cannot always be readily installed in an organization, its success depends on continuous relationships between two different entities 
and not just formal transactions as in the case of formal coordination. It has been found that with an increasing amount of uncertainty and tacit knowledge in $R \& D$ projects, informal approaches become more important to compensate for the lack of explicit knowledge that typically enables the use of formal approaches (Lawrence and Lorsch, 1967; Reger, 1999).

\subsubsection{Hybrid Coordination}

More recently, Reger (1999, 2004) has proposed the concept of hybrid coordination mechanisms. These mechanisms "include some elements of structured self-coordination and trans-departmental relations [...] and cannot be unequivocally classified as structural or informal mechanisms because many of their sub-instruments are either not, or only to some extent, a part of the organizational structure" (Reger, 2004, p. 58). These mechanisms include task forces, interdisciplinary project groups, core programs and core projects as well as technology platforms and promoters. The common nature of these mechanisms is that they are often temporary in nature to achieve a specified goal and cut across the formal organization in that people affected by these mechanisms often come from different organizational parts. A type of hybrid coordination mechanisms can also be modular product architectures. A product architecture is defined as the "scheme by which a product's functions are allocated to its components" (Ulrich, 1995, p. 419). Modular product architectures are characterized by a high degree of decomposability of the product into different components with clearly defined interfaces (Baldwin and Clark, 2000; Chen and Liu, 2005; Gershenson et al., 2003; Ulrich, 1995). In the most extreme case, modular product architectures have a one-to-one mapping from functional elements to the physical components that execute these functions (Ulrich, 1995). Because of that, changes in one component do not affect the functionality of other modules, enabling the independent development of modules. In addition, product modularity entails that interfaces between modules are clearly defined (Baldwin and Clark, 1997; Cabigiosu et al., 2013). Modular product architectures therefore provide a form of embedded coordination which may reduce the overall coordination efforts in product development projects (Cabigiosu et al., 2013; Sanchez and Mahoney, 1996). Product architectures as a means of coordination are ultimately hybrid as their design requires strategic planning and the precise definition of technical interfaces by an interdisciplinary team (e.g. people from $R \& D$, manufacturing, and sales), before physical product development activities can actually take place (Zirpoli and Camuffo, 2009). Finally, product architectures often mirror organization architectures so that they are, at least for some time, part of the organizational structure (Sanchez and Mahoney, 1996). Due to the increased complexity of dispersed R\&D activities of multinational firms, it has been argued that hybrid mechanisms are of increasing importance for the coordination of R\&D (Reger, 2004). 


\subsection{Types and mandates of R\&D units}

Existing literature has typically determined the type and role of a single R\&D subsidiary based on the nature of its tasks (Birkinshaw and Hood, 1998; Kuemmerle, 1997; Nobel and Birkinshaw, 1998). Kuemmerle (1997) for example differentiates between home-base augmenting and home-base exploiting R\&D. In his connotation, the main task of home-base augmenting R\&D units is to absorb and/or create locally developed technological knowledge and feed it back to the headquarters. On the opposite, the main task of home-base exploiting R\&D units is to take advantage of the existing knowledge at the headquarters and apply it in the local context, for example for local product adaptations. Other parameters that have been used to describe the mandate of a subsidiary include the scope of activities, the geographic reach, existing relationships to other units of the $\mathrm{MNC}$, the historical development of the subsidiary, the subsidiary's technological profile, the time-frame and objective of projects, as well as the organizational position within the firm (Chiesa, 2000; Nobel and Birkinshaw, 1998). Depending on the strength of these parameters and especially on the degree to which decision making is centralized, a subsidiary may enjoy a higher or smaller amount of autonomy respectively or may therefore have a higher or smaller mandate (Brooke, 1984; Young and Tavares, 2004). As a consequence, different types of subsidiaries have different levels of autonomy in order to fulfill their mandate (Persaud, 2005).

With respect to the type of $R \& D$ activities and the strategic mandate of a subsidiary, a more fine-grained distinction can be made according to the subsidiary's degree of technology and market orientation. Technology orientation refers to the subsidiary's extent of technology and product development competence and the degree to which it engages in product oriented innovation activities (c.f. Chiesa, 2000; Ronstadt, 1978). Market orientation denotes the subsidiary's extent of market and customer knowledge and the degree to which it engages in market oriented innovation activities (c.f. Håkanson and Nobel, 1993). Technology oriented subsidiaries often engage in product design and technology development while market oriented firms tend to engage in product redesign and adaptation of existing products to local markets. Thus, the degree of technology and market orientation can vary across different $R \& D$ subsidiaries, resulting in different mandates within the company's international $R \& D$ network. Based on this distinction, four core archetypes of R\&D subsidiary mandates can be distinguished which are explained in the following.

\subsubsection{Extended Workbench (EWB)}

At an Extended Workbench, the tasks are assigned by the headquarters to the subsidiary based on short-term opportunities which the headquarters considers as "low-cost extensions". EWBs typically exhibit both a low technology and market orientation, resulting in an overall low mandate. Technical tasks typically include support functions such as documentation services 
or conversion or digitalization of technical drawings with the goal to optimize the firm's overall resource utilization and to benefit from wage cost arbitrage in the host country (Chiesa, 2000; Håkanson and Nobel, 1993). There is often no market orientation at all as the subsidiary provides services for the entire firm and which therefore are not region-specific.

\subsubsection{Local Adaptor (LA)}

This subsidiary type performs product adaptations for local markets which is why it exhibits a low technology but high market orientation. It has the freedom to adapt typically lowcomplex components to local requirements while most of the product's core technologies and systems have been centrally developed at the headquarters. On the other side, the subsidiary has a fairly high market orientation as it is responsible for sensing market-specific requirements and translating them into the product. This headquarters-subsidiary constellation often emerges from existing manufacturing plants which are extended with product development activities to better meet the demands of the local market. This mode is equivalent to Chiesa's (2000) support/adaptive subsidiary which provides technical support to other units or adapts products developed elsewhere in the MNC to local market requirements. It also corresponds to Nobel and Birkinshaw's (1998) local adaptor which has a rather limited development mandate and is rather local in scope.

\subsubsection{Technology Excellence Center (TEC)}

Subsidiaries which are Technology Excellence Centers have often been acquired by the MNC due to technological know-how in a specific area. The TEC is typically in the lead for the advancement and development of a certain technology, thereby showing a high technology orientation. TECs often have a less distinct market orientation as their role is mostly the development of new technologies and products which are not bound to a specific market. TECs represent a blend of Chiesa's (2000) development subsidiaries and research subsidiaries. The development subsidiaries work on projects whose goal is the development of a clearly defined new product. With respect to the geographical scope, the product developed by these subsidiaries may have a local or global reach. Chiesa's (2000) research subsidiaries engage in the exploration of new technologies and accumulation of new knowledge which is not directly related to a single innovation. While some subsidiaries may focus only on a single type of technologies, others may focus on a wide range of technologies. Their geographical scope is typically global as they develop technologies which subsequently are incorporated in different kinds of products. This mode is also equivalent to the combination of Nobel and Birkinshaw's (1998) international adaptor and international creator. While the international adaptor is substantially broader in scope than the local adaptor and engages in development activities for international markets, the international creator engages in research and development and is linked to corporate and divisional R\&D.

\subsubsection{Product Excellence Center (PEC)}


These subsidiaries are virtually independent from the headquarters and develop new technologies and products for local and global markets. Due to these activities, PECs have both a high technology and market orientation which is necessary to meet their mandate. Often, existing technologies and product platforms present in the firm's R\&D network are initially built upon to expand the scope of their own development activities. As a competence center for a range of technologies and/or products, the subsidiaries often develop the product's architecture and collaborate with other entities in the development of specific subsystems or components. As such, the site is often equivalent to the MNC's headquarters regarding the range of competencies and responsibilities. At the same time, PECs are often profit-and-loss centers and are responsible for worldwide sales, which also results in a high market orientation.

Depending on the activities that the different subsidiary types perform and considering their technology and market orientation, the four subsidiary archetypes can be juxtaposed in the following scheme which serves as a reference framework for our further analysis.

\section{<insert figure 1 about here>}

\section{Method and Data}

Despite existing empirical work on coordination mechanisms in multinational firms, past investigations have mostly employed large scale surveys. While this approach has produced valuable insights in the type and intensity of the coordination mechanisms used, it neglects the often unique circumstances in which global $R \& D$ projects are conducted (e.g., specific $R \& D$ tasks or location-specific parameters). Therefore, we chose an exploratory approach using qualitative case studies according to Eisenhardt (1989) and Yin (2003). Case studies help discovering causal relationships between different topics which cannot be obtained through purely quantitative surveys as they allow for deeper insights in how and why companies choose a certain approach (Siggelkow, 2007; Yin, 2003). Through case study research we are thus able to obtain deeper insights in how the mandate of $R \& D$ subsidiaries influences coordination mechanisms in the MNC.

\subsection{Case Sampling and Overview}

In order to answer the research question we searched for multinational companies whose international $\mathrm{R} \& \mathrm{D}$ activities ranged from simple technical support, simple customer and market oriented development activities, complex product and technology oriented development activities, to fully-fledged research activities. The companies were sampled from a database which our institute maintains for research purposes on the management of global 
R\&D. The initial sample size included 40 companies which matched our criteria of maintaining international $R \& D$ operations, were active in the medium to high-tech industries according to the OECD definition (2005), and whose international R\&D operations had been running for at least ten years. We ultimately selected those firms to which we had the best data access in terms of provision of in-depth access to firm-internal data on the R\&D strategy and organization. We deliberately did not consider the pharmaceutical or chemical industries as their global R\&D strategies and product architectures differ completely from the industries in our sample. This process resulted in nine firms which served as the basis for our further analysis. The industries represented by the firms include the machine tooling, medical devices, and IT hardware industries (see table 1). The names of the firms have been disguised to due confidentiality reasons.

\section{<insert table 1 about here>}

Company A develops machines for the processing and printing of bank notes for international customers and markets. The product's architecture is highly complex and entails a wide range of different technologies. With about 10.000 employees, $A$ is present with R\&D in six countries. Company B is a firm active in the development of machines and instruments for medical diagnosis purposes. The products are highly complex and include among others robotics, sensor, X-ray, and imaging technologies. With an R\&D quota of about 7,5\%, B generates a turnover of 1,5 billion USD worldwide. Company $\mathrm{C}$ is also active in the development of medical equipment products for therapy and diagnosis purposes. The core product is a medium-tech imaging device whose quality and performance is largely software driven. C has about 7000 employees in four countries. Company D is a developer and manufacturer of heavy-duty mining vehicles. The products consist of a large amount of systems and components and cover a wide range of technologies. D has about 5000 employees and is present with $R \& D$ activities in five countries. Company $E$ develops and manufactures products for the diagnosis and treatment of oncological diseases. The products' architecture is highly complex and contains a wide range of electrical and mechanical components which are steered by software-based control systems. E has R\&D facilities in six countries and employs about 3000 people. Company $\mathrm{F}$ is a manufacturer of electrocardiographic and ultrasound devices for the medical diagnosis. The products integrate a large amount of electrical, mechanical, hardware and software components. F employs about 12.000 people worldwide and has $\mathrm{R} \& \mathrm{D}$ sites in nine countries around the globe. Company $\mathrm{G}$ is a developer and manufacturer of IT equipment for personal and professional use. The products are mostly based on established technologies which are embedded in rather low-complex products. G maintains R\&D sites in five countries and employs about 7.000 
people worldwide. Company $\mathrm{H}$ is active in the medical and safety business where it is specialized on the development of breathing apparatuses. $\mathrm{H}$ has four international $\mathrm{R} \& \mathrm{D}$ sites and employs about 6000 people worldwide. Company I is a developer and manufacturer of electronic high-precision instruments which are strongly software-driven. I has more than 12.000 employees worldwide and has R\&D centers in five different countries.

\subsection{Data Collection}

To get initial insights on the international organization of the R\&D function we first conducted interviews with representatives of the $R \& D$ headquarters and subsidiaries including CTOs, heads of R\&D, technology managers and innovation managers. In total, we conducted 36 interviews with headquarter managers and 20 interviews with subsidiary managers of the nine selected firms during the entire course of the data collection and verification (see table 1). This provided a holistic and fine-grained picture of the case firms' $\mathrm{R} \& \mathrm{D}$ organizations including the role of the different sites as well as the products that were being developed in the R\&D network. In a second step we analyzed the task distribution between the headquarters and the different subsidiaries. In particular, we investigated how headquarters coordinated the activities in different $R \& D$ subsidiary mandates. To this end, we asked both the headquarters' representatives as well as R\&D managers within the subsidiaries how R\&D tasks and responsibilities were defined within the company. Using a semistructured interview guideline, our lead questions focused on the way of interaction between headquarters and subsidiary prior to and during technology and/or product development projects, the decision making process for strategic product development projects, and the range of activities and thus the role of the subsidiary within the firm's international R\&D network. These questions lead to rather open discussions about the work procedures of the headquarters and the subsidiary within the network. All interviews were performed face-toface or via telephone and video conference and lasted from 60 minutes to 90 minutes. They were tape recorded in order to facilitate further analysis.

\subsection{Data Analysis}

The data collected during the research process were continuously entered in a case database. When the data collection of one firm was completed, we synthesized all firm data into an individual case history. The case histories were on average 12 pages in length and included narrative, selected quotes from the respondents as well as tables summarizing key facts. According to Eisenhardt (1989), we subsequently performed a within-case analysis to arrive at the essential mechanisms through which the firms employed their headquarters-subsidiary 
coordination. Together with two other research assistants, independent and individual perceptions of the single cases were formed and subsequently discussed within a cross-case comparison. For this step, we used pairwise comparison and tabulated the data to improve the visibility of emerging themes (Miles and Huberman, 1994). We iteratively discussed the emerging themes and revisited existing literature to finally agree on key topics and coordination approaches which were common across all cases. We also shared our emerging insights with our informants to see if we had interpreted the data correctly and performed follow-up interviews in cases where initial interpretations deviated from the respondent's perception. The themes which ultimately emerged then served as the base for further analysis.

\section{Findings}

Table 2 summarizes the cases regarding the subsidiaries' core activities as well as the coordination activities used between the headquarters and the subsidiary. The findings suggest that different R\&D subsidiary mandates call for different coordination approaches.

\section{<insert table 2 about here>}

Figure 1 shows the spread of the case firms according to their subsidiaries' strategic mandate as determined by their degree of technology and market orientation. In general, a subsidiary's mandate was considered to be low when it exhibited low market and technology orientation (as with Extended Workbenches). It was considered medium if only one dimension exhibited a high level (as with Local Adaptors and Technology Excellence Centers), and high if both market and technology orientation were high (as with Product Excellence Centers). The findings show that R\&D activities in market-oriented subsidiaries consistently involved modifications at the component and module level. In contrast, technology-oriented subsidiaries engaged in considerable development activities at the subsystems level or were responsible for the development of the entire product architecture and consequently possessed a broad range of technological competences not found elsewhere in the MNC.

\section{<insert figure 2 about here $>$}

The findings furthermore show that each archetypal subsidiary mandate is coordinated by a persistent set of coordination mechanisms, which are described in the following.

Extended Workbench. The subsidiaries in firms A and B were characterized by a low technology and low market orientation and in fact were given very little autonomy from the headquarters. Their responsibilities entailed the modification or development of components and software according to the specifications provided by the headquarters. Besides the low 
complexity of the technological tasks, A and B had no market orientation but delivered their results directly to the headquarters, rendering them an Extended Workbench. Formal coordination in these EWBs occurred mainly through strong central decision making followed by a strict control of the subsidiary's work output and regular meetings between senior managers of the headquarters and the subsidiary. Informal coordination mechanisms were virtually absent due to the low complexity of the tasks, the limited responsibilities of the subsidiary engineers, and virtually no collaboration with other R\&D sites. In both A and B the product's modular architecture specified large fractions of the scope and depth of the subsidiaries' R\&D activities. For example, in firm A, the product's technical interfaces between the sensor modules and the cash processing system were described in technical drawings and written documents in which the geometrical and physical dimensions were exactly specified. Furthermore, the sensors were built on established technologies which were used in other products as well and thus had standardized interfaces. As a consequence, the subsidiary was able to develop the sensor module according to the specifications for the module and its interfaces. Because of the clear specifications, the subsidiary did not have to obtain any further approval by the headquarters which in turn merely controlled the subsidiary's final results in terms of the engineered module. Similarly, at firm B, the software developed at the subsidiary for the imaging system was independent of other systems' functionality and could therefore be programmed autonomously. This allowed the headquarters to focus on the software's ultimate functionality rather than constantly controlling the progress of the software development. At B, informal coordination was virtually absent or limited to a few personal contacts between headquarters and subsidiary engineers.

Local Adaptor. In cases of low technology and high market orientation of the subsidiary, as was the case with firms D and G, a large amount of the subsidiaries' $R \& D$ activities were coordinated by central decision making at the headquarters. Here, the subsidiaries' mandate was the local adaptation of a core module (i.e., the beam and shovel) in the case of firm D and of specific components (e.g. the housing of a pointing device) in the case of firm G. The headquarters in both firms controlled the subsidiaries' output in terms of the technical performance of the locally adapted, final product. Compared to the EWB, the headquarters' definition of the tasks was limited to the module's/component's interfaces while leaving the way how the modules and components were adapted in the responsibility of the subsidiaries. Similar to the EWB, informal coordination approaches were virtually absent in the LA. As with EWBs, the headquarters defined the product architecture including the interfaces of the subsystems and modules and subsequently forwarded the technical specifications to the subsidiaries. This resolved large parts of the firms' overall coordination efforts and was particularly apparent in case $\mathrm{D}$ where the headquarters precisely defined the range of how the subsidiary could adapt the beam and shovel of an existing excavator to local market 
requirements. Here, the headquarters distinguished between system know-how and technologies on the one side and modules and components - which were not "system-relevant" - on the other side, i.e., which had no impact on the product's core architecture and functionality in case a module was changed by the subsidiary. Through this, the headquarters were able to provide the subsidiary with detailed technical plans about the module boundaries. This enabled the subsidiary to perform technical module and component adaptations without the need for an official approval by the headquarters.

Technology Excellence Center. The subsidiaries of the firms C, E, and $\mathrm{H}$ heavily engaged in the development of important subsystems of the final product and therefore were the competence centers for specific technologies. At the same time, the subsidiaries were not market oriented as all products were global products and not designed for local adaptations. Compared to the EWB and LA, the TECs in $\mathrm{C}, \mathrm{E}$, and $\mathrm{H}$ enjoyed a high amount of autonomy from the headquarters regarding the development of technologies and subsystems for which they were responsible. Formal coordination of the R\&D activities was achieved through the adherence of all involved subsidiaries to a common innovation process. In contrast to the EWB and LA, the headquarters emphasized the definition of work procedures and regular meetings rather than formally controlling the subsidiaries' output. Furthermore, the TECs engaged in regular physical and virtual meetings with the headquarters to update them on technological developments which might affect the overall system. Informal coordination occurred mainly through socialization in that the TECs and the headquarters shared a very profound understanding of the final product's quality and performance requirements. In particular, increased communication was performed in later stages of the subsystem development prior to the subsystem's integration in the overall system. Just as in the cases of the EWB and the LA, the modular product architectures that were shared between the headquarters and the subsidiaries of the firms enabled the TECs to perform their subsystem responsibilities quite autonomously. For example, at firm E, each subsidiary was the center of excellence for a specific subsystem (i.e., treatment delivery system, information system, imaging system, and treatment planning system). Here, all R\&D activities were coordinated by a systems integration team which also was the architect of the overall system and thus defined the product architecture. This constellation enabled the subsidiaries to work independently while the systems integration team coordinated the different activities in order to develop the final system. Similarly at $\mathrm{C}$ and $\mathrm{H}$, the subsystems (i.e., image systems and oxygen detection system respectively) were completely independent of the rest of the product and only connected through the controller unit in which the data were processed. Therefore, the R\&D activities could be largely performed based on the interface requirements imposed by the controller unit.

Product Excellence Center. The high technology and market orientation of the PECs of firms $\mathrm{F}$ and I conferred a high degree of autonomy on them including a wide range of product 
and market activities. From a product perspective, the PECs were responsible for the complete design of a new product line. From a market perspective, their activities entailed sourcing and worldwide sales responsibilities. Due to this high autonomy from the headquarters, the only formal coordination mechanism in both firms entailed regular strategy meetings between top managers from the headquarters and the PECs. These meetings served as an exchange platform for relevant technological, product, and market information. Informal coordination activities occurred particularly in the later stages of the product development process for know-how exchange as well as during product portfolio decisions when the TEC's new product plans were aligned with the overall firm strategy. In these cases, product managers and sales people from the headquarters and subsidiaries frequently interacted to align different product line strategies. An important informal coordination mechanism was embodied in the headquarters' and subsidiaries' common understanding of the firm's overall product strategy, portfolio, and product architecture. Despite the PECs' high autonomy, they often relied on the technologies and product platforms existing in the firm network and built new product lines based on them. Thus, formal coordination activities were limited to a few, regular top management meetings while informal coordination occurred much more on a team and personal level regarding the interaction of engineers. In the cases of firms $F$ and $I$, and in contrast to the EWB, LA, and TEC, the product architectures were defined at the subsidiaries so that coordination was reduced to the exchange of important technical and market-related outcomes.

\section{Discussion}

\subsection{The impact of subsidiary mandate on the use of formal and informal coordination mechanisms}

Generally, it appears that headquarters use formal mechanisms to coordinate their overseas $R \& D$ activities in cases where the subsidiary has a low technology orientation, as is true for Extended Workbenches and Local Adaptors. At EWBs, precise task definition (i.e., centralization of decision making) as well as controlling the results of the subsidiary (i.e., output control) were dominant vehicles to coordinate the subsidiaries' tasks. Furthermore, for both the EWBs and LAs, central decision making pertaining to the design of the product strategy and architecture was a key mechanism for headquarters to coordinate their subsidiaries' activities. In addition, at EWBs, the central decision making by the headquarters also concerned customer and market strategies, meaning that the EWBs were merely executing simple, pre-defined tasks on behalf of the headquarters. In contrast, at LAs, the headquarters defined the product's subsystems and interfaces but allowed the subsidiary to independently perform adaptations which did not affect the product's core architecture. These activities were typically at the component or module level of the final product and thus 
affected only the subsystem in which they were embedded but did not affect the functionality between subsystems. Overall, the formal coordination efforts were therefore reduced relative to the EWB. It appears that formal rather than informal coordination is an efficient approach to coordinate low-complex, market oriented R\&D activities. Relative to product architecture and subsystem design, component or module design is rather low-complex because their modularity limits interactions with higher-order systems to the interface with only one superordinate subsystem (Chen and Liu, 2005). As such, component and module design form a 'black box' which can be autonomously handled without constant interaction with other design teams in the organization (Brusoni and Prencipe, 2001; Sanchez and Mahoney, 1996). Due to the explicitness and modularity of R\&D activities at the component or module level compared to higher-order systems, they are suited for formal coordination by means of providing technical specifications, output control, and planned exchange within established processes. Therefore, we propose:

Proposition la: In global $R \& D$ organizations, the headquarters will use more formal mechanisms to coordinate the subsidiary's $R \& D$ activities the lower the subsidiary's technological and market orientation.

With increasing technology orientation central decision making diminished as a coordination mechanism and was increasingly replaced by decentral decision making. For example, in the case of Technology Excellence Centers, the headquarters still defined the overall system, but the subsidiaries were responsible for defining and advancing the subsystem for which they were the competence center. Similarly, also the use of specific control types as formal coordination mechanisms changed with higher subsidiary mandates: while the headquarters use output control at subsidiaries with low mandates, they use process or behavioral control with higher mandates. For example, in the Extended Workbenches of firms A and B, the headquarters typically controlled the activities at the subsidiary regarding time and quality. In contrast, in the TECs of firms $\mathrm{C}, \mathrm{E}$, and $\mathrm{H}$, the headquarters met more frequently with the subsidiary to stay informed about the latest subsystem development activities. This situation is even more aggravated in cases of the PECs where coordination on part of the headquarters was reduced to a minimum and more market-oriented aspects as the subsidiary's technical activities were not subject for integration in a product that was shared across several organizational units. The reason for using more informal coordination mechanisms can be explained by the nature of the tasks of subsidiaries with high technological mandates: in contrast to activities at the component and module level, which are typically quite modular, the design of product architectures including the definition of the interfaces between the subsystems to make an entire product work requires knowledge about diverse disciplines (e.g., electronics, software, hardware, etc., as in our cases) and the way they interact (Brusoni and Prencipe, 2001; Henderson and Clark, 1990; MacDuffie, 2013). These activities often involve some degree of uncertainty due to feedback loops between different systems and technologies. 
At TECs and PECs, the technological competence is located at the subsidiary and the tasks are rather complex and characterized by uncertainty. In this situation, outcome control is very difficult as the headquarters does not possess the technological know-how to define a specific outcome a priori. Therefore, formal coordination is not meaningful in R\&D activities where input factors (such as, e.g., technological know-how) and output factors (e.g., technical results) are not predictable or change frequently (Henderson and Clark, 1990; McDermott and O'Connor, 2002). Moreover, in early stages of technology and product development, excessive formal coordination measures can even hinder innovation (Reger, 2004). Therefore, headquarters used informal approaches by means of on-demand personal and virtual exchange to compensate for the uncertainties involved in the subsidiaries' product development activities. Furthermore, an informal coordination mechanism as used by the TECs was the well-developed understanding of the product strategy and architecture, and the requirements that technology and architecture development activities are expected to deliver. It appears that this shared understanding is a form of socialization where common work approaches, embodied in the product strategy and architecture, serve as an important, tacit coordination mechanism. Therefore, we propose:

Proposition 1b: In global $R \& D$ organizations, the headquarters will use more informal mechanisms to coordinate the subsidiary's $R \& D$ activities the higher the subsidiary's technology and market orientation.

\subsection{Product modularity as a hybrid coordination mechanism}

In all firms, the final products were highly modular in that they consisted of a set of subsystems, modules, and components whose technical interfaces were clearly defined and which could function largely independent from each other. In the case of the EWBs, R\&D activities at the subsidiaries involved the development of a physical component which performed a specific function (a sensor in firm A and software code in firm B), in the case of LAs a component or module (a beam in firm $D$ and housing in firm $G$ ), in the case of TECs entire subsystems (image system in firm $\mathrm{C}$ and treatment planning system in firm $\mathrm{C}$ ), and in the case of PECs entire products (ultrasound devices in firm $\mathrm{F}$ and high-precision weighing scales in firm I). In all cases, the modularity of the product architecture created distinct elements of the final product that allowed the subsidiaries to perform their R\&D activities independent of the headquarters, yet confined within the boundaries set by the interfaces. While these boundaries are very small for EWBs, they are quite extensive for TECs and PECs. These findings support the argument that the product architecture and the specific definition of the interaction relationships between subsystems and modules may serve as a coordination mechanism which may be of high value for firms with complex products (Brusoni, 2005; Brusoni and Prencipe, 2001). In particular, the rules and specifications embedded in modular 
product architectures have the power to replace some of the coordination activities which otherwise would have to be carried out in order to integrate the dispersed R\&D activities (Sanchez and Mahoney, 1996). Our findings confirm this assumption when comparing the firms with low and high technology orientation: at EWBs and LAs, the headquarters are able to exclusively employ formal mechanisms to coordinate the subsidiaries' component and module design activities as their technical specifications are so explicit that other, more informal forms of coordination become largely unnecessary. In contrast, the headquarters at TECs and PECs largely used informal mechanisms to coordinate the subsidiaries' system and product design activities as the scope of these activities was much larger and implicit and interface definitions by the headquarters were limited to the systems level. As a consequence, formal activities become increasingly difficult the more subsidiaries engage in system-level $\mathrm{R} \& \mathrm{D}$ activities. Thus, modular product architectures with clearly defined technical interfaces partially substitute and thus lower the headquarters' formal coordination efforts. Therefore, we propose:

Proposition 2a: In global $R \& D$ organizations, the higher the product modularity, the lower will be the headquarters' formal and informal coordination effort to integrate the $R \& D$ activities of the subsidiary.

A core benefit of modular product architectures is furthermore their potential to generate highly localized solutions while taking advantage of the technical know-how present in other parts of the MNE's R\&D organization. Especially in the cases of EWBs and LAs, the existing product architecture with its standardized interfaces even down to the module level enabled the subsidiaries to freely design solutions which were customized for unique market requirements. In the case of firm $\mathrm{D}$, the subsidiary was free to source raw materials locally and design the beam of the excavator in accordance to only the weight and the connection to the tower. During the design of the overall product architecture, the beam was judged uncritical to the functionality of the rest of the product which is why the subsidiary was allowed to design the beam module freely. The same is true in firm $\mathrm{G}$ where the housing of the pointing device had to adhere to a few design parameters. As this module was not critical for the overall functionality of the device, the subsidiary was able to design a housing which appealed to the local market without greater interference by the headquarters. The situation was a bit different for TECs and PECs whose mandate was inherently to develop systems or entire architectures. Similar to platform development (Meyer, 1997; Muffatto and Roveda, 2000), the goal of the TECs and PECs in this study was to develop systems or architectures which could be leveraged across the entire R\&D organization. Thus, high modularity, especially at the module level, allows high local adaptation while keeping formal and informal coordination efforts low due to the specifications inherent in standardized interfaces. Therefore, we postulate: 
Proposition 2b: In global $R \& D$ organizations, the higher the product modularity, the higher will be the firm's ability to adapt products to local market requirements.

Finally, across all subsidiary mandates, the data suggest that modular product architectures have a negative effect on the intensity of the use of formal and informal coordination mechanisms. The relationship between decreasing formal and increasing informal coordination with higher subsidiary mandates as well as the effect of modular product architectures as a means of hybrid coordination is illustrated in figure 3: the absolute amount of formal coordination efforts $C_{F}$ decreases and informal efforts $C_{I}$ increases with higher subsidiary mandates, resulting in the total amount of coordination effort $\mathrm{C}_{\mathrm{T}}$. Furthermore, the use of hybrid coordination measures may effectively reduce the total amount of coordination efforts, resulting in the new curve $\mathrm{C}_{\mathrm{T}, \mathrm{H}}$. The shape of the curves is concave as the marginal, formal coordination efforts for higher subsidiary autonomy is likely to decrease while the marginal, informal coordination efforts increase.

\section{<insert figure 2 about here>}

\section{Conclusion}

This article explored and formally developed propositions about the relationship between the subsidiary's mandate of a multinational firm and the coordination mechanisms which the headquarters apply to integrate the dispersed R\&D activities into one final product. Based on nine case studies of MNCs, we find that the use of formal or informal coordination mechanisms varies with different subsidiary mandates as determined by its degree of technology and market orientation. Formal coordination mechanisms - particularly central decision making, planning, and output control - are predominantly used by headquarters for subsidiaries with a low mandate. For subsidiaries with high mandates, formal coordination mechanisms are heavily supplemented with informal coordination mechanisms. Finally, the findings show that modular product architectures are a powerful vehicle to coordinate dispersed subsidiary activities and have the potential to lower overall coordination efforts in the MNE.

\subsection{Implications for theory and practice}

The findings of this study contribute to extant literature on the management of multinational firms in general and literature on global $R \& D$ management in particular. First, this study 
extends existing research on coordination in multinational firms by investigating which formal, informal, and hybrid coordination mechanisms are used in different subsidiary mandates. Second, the findings of our study also point to the importance of product architecture as a vehicle to coordinate dispersed $R \& D$ activities. While up to now the topics of product architecture and platform management have mainly been treated from a manufacturing perspective (e.g. Ulrich and Pearson, 1998) or general product innovation perspective (e.g. Mikkola and Gassmann, 2003; Ulrich, 1995), this study also indicates that modular product architectures serve as a hybrid coordination mechanism and effectively lower overall coordination efforts in the multinational firm. Thus, effective work in global R\&D organizations calls for increased product modularization (Persson and Ahlström, 2006).

The findings have also valuable implications for managers and $R \& D$ leaders in multinational firms. First, the description of the different subsidiary mandates and the coordination mechanisms used therein provides a good picture of the necessary or possible coordination activities and may help managers to decide which mechanisms are most appropriate in a given subsidiary setting. Second, the beneficial effects of modular product architectures in globally dispersed $R \& D$ activities point to the importance of well-designed and decomposable product architectures. High levels of modularity, especially at the module level, put the firm into the position to adapt products to local market requirements more easily than for non-modular products. In addition, as modules often are not critical for the overall functionality of the product, the costs for coordinating local adaptation activities will be much lower. Therefore, $\mathrm{R} \& \mathrm{D}$ managers may wish to revisit their product architectures and develop product designs which facilitate the separability of component, module, and subsystem development. In this way, R\&D activities can be performed autonomously without overt managerial attention and running the risk of damaging the functionality of the entire product system.

\subsection{Limitations and future research}

Naturally, the findings of this study need to be considered in the light of several limitations. First, the study is based on a limited number of case studies entailing companies of different industries. Thus, a study involving a larger sample of companies including other industries like pharmaceuticals, chemical industry or consumer goods might be useful to confirm or moderate these results. Further quantitative results measuring the costs of coordination (e.g., working time, interaction costs, travel expenses, logistics costs) might help companies to find an optimal setting for the interaction between different R\&D sites. Another promising research avenue is the question how product architecture affects other topical themes in the management of global R\&D. For example, it would be interesting to investigate how new technologies emerging in the firm's international R\&D network can best be integrated into 
existing product development processes and product architectures or which effects different product architectures have on the staffing of foreign $R \& D$ subsidiaries.

Finally, despite the benefits of modular product architectures for the MNE's overall coordination effort, it must be pointed out that designing architectures including the specification of the interfaces is an act of coordination per se and typically takes place in the early stages of any product development project (Persson and Ahlström, 2006). Consequently, lower coordination efforts by means of increased product modularity can only become effective when modularity has already been implemented in the design of the product architecture (MacDuffie, 2013). Therefore, notwithstanding the insights generated by this study, it would be interesting to investigate potential trade-offs between a very fine-grained design of modular product architectures and the benefits these generate in later stages of the development process, particularly in global R\&D organizations. Based on this, another promising research avenue is to investigate how product modularity is generated and, in the light of the above argument, if there is an optimum for product modularity which safeguards global effectiveness and local responsiveness at the same time. 


\section{Literature}

Ambos, B., Schlegelmilch, B.B., 2007. Innovation and control in the multinational firm: A comparison of political and contingency approaches. Strategic Management Journal 28, 473-486.

Archibugi, D., Iammarino, S., 1999. The policy implications of the globalisation of innovation. Research Policy 28, 317 - 336.

Asakawa, K., 2001. Evolving headquarters-subsidiary dynamics in international R\&D: the case of Japanese multinationals. R\&D Management 31, 1-14.

Baldwin, C.Y., Clark, K.B., 1997. Managing in an age of modularity. Harvard Business Review 75, 84.

Baldwin, C.Y., Clark, K.B., 2000. Design rules: The power of modularity. Mit Press.

Bergek, A., Bruzelius, M., 2010. Are patents with multiple inventors from different countries a good indicator of international R\&D collaboration? The case of ABB. Research Policy 39, 1321 - 1334.

Birkinshaw, J., 1996. How Multinational Subsidiary Mandates Are Gained and Lost. Journal of International Business Studies 27, 467-495.

Birkinshaw, J., Hood, N., 1998. Multinational Subsidiary Evolution: Capability and Charter Change in Foreign-Owned Subsidiary Companies. The Academy of Management Review 23, 773-795.

Brooke, M.Z., 1984. Autonomy and Centralization in Multinational firms. International Studies of Management \& Organization 14, 3-22.

Brusoni, S., 2005. The Limits to Specialization: Problem Solving and Coordination in 'Modular Networks'. Organization Studies 26, 1885-1907.

Brusoni, S., Prencipe, A., 2001. Unpacking the black box of modularity: technologies, products and organizations. Industrial and Corporate Change 10, 179-205.

Cabigiosu, A., Zirpoli, F., Camuffo, A., 2013. Modularity, interfaces definition and the integration of external sources of innovation in the automotive industry. Research Policy 42, 662-675.

Chen, K.-M., Liu, R.-J., 2005. Interface strategies in modular product innovation. Technovation 25, 771-782.

Chiesa, V., 2000. Global R\&D project management and organization: a taxonomy. Journal of Product Innovation Management 17, 341-359.

Child, J., 1973. Predicting and understanding organization structure. Administrative Science Quarterly, 168-185.

Cray, D., 1984. Control and Coordination in Multinational Corporations. Journal of International Business Studies 15, 85-98.

De Meyer, A., Mizushima, A., 1989. Global R\&D Management. R \& D Management 19, 135146. 
Eisenhardt, K.M., 1989. Building theories from case study research. Academy of Management Review 14, 532-550.

Gassmann, O., von Zedtwitz, M., 1999. New concepts and trends in international R\&D organization. Research Policy 28, 231-250.

Gershenson, J.K., Prasad, G.J., Zhang, Y., 2003. Product modularity: definitions and benefits. Journal of Engineering Design 14, 295.

Håkanson, L., Nobel, R., 1993. Determinants of foreign R\&D in Swedish multinationals. Research Policy 22, 397-411.

Henderson, R.M., Clark, K.B., 1990. Architectural Innovation: The Reconfiguration of Existing Product Technologies and the Failure of Established Firms. Administrative Science Quarterly 35, 9.

Kahn, K.B., 1996. Interdepartmental integration: a definition with implications for product development performance. Journal of Product Innovation Management 13, 137-151.

Kuemmerle, W., 1997. Building Effective R\&D Capabilities Abroad. Harvard Business Review 75, 61-70.

Lawrence, P.R., Lorsch, J.W., 1967. Differentiation and Integration in Complex Organizations. Administrative Science Quarterly 12, 1-47.

MacDuffie, J.P., 2013. Modularity-as-Property, Modularization-as-Process, and 'Modularity'as-Frame: Lessons from Product Architecture Initiatives in the Global Automotive Industry. Global Strategy Journal 3, 8-40.

Malone, T.W., Crowston, K., 1994. The interdisciplinary study of coordination. ACM Computing Surveys (CSUR) 26, 87-119.

Manolopoulos, D., Söderquist, K.E., Pearce, R., 2011. Coordinating decentralized research and development laboratories: A survey analysis. Journal of International Management 17, 114-129.

Martinez, J.I., Jarillo, J.C., 1989. The Evolution of Research on Coordination Mechanisms in Multinational Corporations. Journal of International Business Studies 20, 489-514.

Martinez, J.I., Jarillo, J.C., 1991. Coordination Demands of International Strategies. Journal of International Business Studies 22, 429-444.

McDermott, C.M., O'Connor, G.C., 2002. Managing radical innovation: an overview of emergent strategy issues. Journal of Product Innovation Management 19, 424.

Meyer, M.H., 1997. The power of product platforms. Simon and Schuster.

Mikkola, J.H., Gassmann, O., 2003. Managing modularity of product architectures: toward an integrated theory. IEEE Transactions on Engineering Management 50, 204 - 218.

Miles, M.B., Huberman, A.M., 1994. Qualitative data analysis: An expanded sourcebook, 2nd ed. Sage Publications, Thousand Oaks.

Muffatto, M., Roveda, M., 2000. Developing product platforms:: analysis of the development process. Technovation 20, 617-630. 
Nobel, R., Birkinshaw, J., 1998. Innovation in multinational corporations: control and communication patterns in international R\&D operations. Strategic Management Journal 19, 479-496.

OECD, 2005. Classification of manufacturing industries based on technology, in: OECD Science, T.a.I.S. (Ed.).

Ouchi, W.G., Maguire, M.A., 1975. Organizational control: Two functions. Administrative Science Quarterly, 559-569.

Persaud, A., 2005. Enhancing Synergistic Innovative Capability in Multinational Corporations: An Empirical Investigation. Journal of Product Innovation Management 22, 412-429.

Persson, M., Ahlström, P., 2006. Managerial issues in modularising complex products. Technovation 26, 1201 - 1209.

Reger, G., 1999. How R\&D is coordinated in Japanese and European multinationals. R\&D Management 29, 71-88.

Reger, G., 2004. Coordinating globally dispersed research centres of excellence-the case of Philips Electronics. Journal of International Management 10, 51-76.

Ronstadt, R.C., 1978. International R\&D: the establishment and evolution of research and development abroad by seven US multinationals. Journal of International Business Studies, 7-24.

Sanchez, R., Mahoney, J.T., 1996. Modularity, flexibility, and knowledge management in product and organization design. Strategic Management Journal 17, 63-76.

Siggelkow, N., 2007. Persuasion with case studies. Academy of Management Journal 50, 20.

Srikanth, K., Puranam, P., 2011. Integrating distributed work: comparing task design, communication, and tacit coordination mechanisms. Strategic Management Journal 32, 849 -875 .

Thompson, J.D., 1967. Organizations in Action: Social Science Bases of Administrative Theory. Transaction Publishers, New Brunswick, NJ.

Ulrich, K., 1995. The role of product architecture in the manufacturing firm. Research Policy 24, 419-440.

Ulrich, K., Pearson, S., 1998. Assessing the importance of design through product archeology. Management Science 44, 352 -369.

Yin, R.K., 2003. Case Study Research - Design and Methods. Sage Publications, Thousand Oaks, London, New Dehli.

Young, S., Tavares, A.T., 2004. Centralization and autonomy: back to the future. International Business Review 13, 215-237.

Zirpoli, F., Camuffo, A., 2009. Product architecture, inter-firm vertical coordination and knowledge partitioning in the auto industry. European Management Review 6, 250-264. 


\section{Appendix}

Table 1: Overview of interviews

\begin{tabular}{|c|c|c|c|}
\hline Company & $\begin{array}{l}\text { Headquarter Location } \\
\text { (\# of interviews) }\end{array}$ & $\begin{array}{l}\text { Subsidiary Location } \\
\text { (\# of interviews) }\end{array}$ & Interview partners $^{a}$ \\
\hline Company A & Germany (6) & Russia (4) & $\begin{array}{l}\text { HQ: head of R\&D, heads of systems development; } \\
\text { SUB: branch manager, technical manager }\end{array}$ \\
\hline Company $\mathrm{C}$ & Germany (5) & USA (3) & $\begin{array}{l}\text { HQ: head of R\&D, head of systems integration; } \\
\text { SUB: head of system development, branch manager }\end{array}$ \\
\hline Company E & USA (3) & Switzerland (2) & $\begin{array}{l}\text { HQ: Head of systems integration, head of R\&D; } \\
\text { SUB: head of system development, systems engineer }\end{array}$ \\
\hline Company F & USA (3) & China (3) & $\begin{array}{l}\text { HQ: Head of global research, head of division; } \\
\text { SUB: project leader, project engineer }\end{array}$ \\
\hline Company I & Switzerland (3) & China (1) & $\begin{array}{l}\text { HQ: Head of R\&D, head of marketing; } \\
\text { SUB: project member }\end{array}$ \\
\hline
\end{tabular}

${ }^{\mathrm{a}} \mathrm{HQ}$ : headquarters; SUB: subsidiary 


\section{Tables and Figures}

Table 2: Overview of case firms and interviews

\begin{tabular}{|c|c|c|c|}
\hline Company & Industry & Turnover $^{a}$ & Subsidiary's $R \& D$ mandate $^{b}$ \\
\hline Company A & bank note machines & 2.5 & $\begin{array}{l}\text { Extended Workbench: no technology, product, or market responsibility. SUB engineers a specific sensor for } \\
\text { banknote detection according to HQ specifications. Final product (bank note sorter) is based on one global } \\
\text { platform and designed only for minimal adaptations. }\end{array}$ \\
\hline Company B & medical devices & 1.5 & $\begin{array}{l}\text { Extended Workbench: no technology, product, or market responsibility. SUB develops software code for } \\
\text { imaging system as part of the final product according to HQ specifications. Final product (computed } \\
\text { tomography system) has a global market and does not allow for local adaptations. }\end{array}$ \\
\hline Company $\mathrm{C}$ & medical devices & 1.5 & $\begin{array}{l}\text { Technology Excellence Center: extensive technology development but no market responsibility. SUB designs } \\
\text { and develops a major system (image system) of the final product (x-ray equipment). Product has a global market } \\
\text { and does not allow for regional adaptations. }\end{array}$ \\
\hline Company D & construction vehicles & 4.2 & $\begin{array}{l}\text { Local Adaptor: no technology or product development, but high market responsibility. SUB engineers } \\
\text { peripheral product modules (beam and shovel, amongst other) for final product (excavator). It adapts an existing } \\
\text { module to local market needs, engages in local sourcing, and is responsible for local sales. }\end{array}$ \\
\hline Company E & medical devices & 2.6 & $\begin{array}{l}\text { Technology Excellence Center: extensive technology development but no market responsibility. SUB designs } \\
\text { and develops a major system (e.g. treatment system) of the final product (oncology treatment device). Product } \\
\text { does not allow for regional adaptations. }\end{array}$ \\
\hline Company F & medical devices & 18.1 & $\begin{array}{l}\text { Product Excellence Center: high technology and product development responsibility as well as global market } \\
\text { responsibility. SUB designs and develops new product architectures (for ultrasound devices) and technologies. } \\
\text { It develops products for different markets and is responsible for worldwide sales. }\end{array}$ \\
\hline Company G & IT hardware & 2.2 & $\begin{array}{l}\text { Local Adaptor: no technology, very limited product adaptation, and high market responsibility. SUB adapts } \\
\text { product features (e.g. housing design) of final product (e.g. pointing device) for emerging countries } \\
\text { requirements and is responsible for sales in all emerging countries. }\end{array}$ \\
\hline Company $\mathrm{H}$ & medical devices & 3.2 & $\begin{array}{l}\text { Technology Excellence Center: extensive technology development, but no market responsibility. SUB designs } \\
\text { and develops a major system (oxygen detection) while HQ has system integration competence of final product } \\
\text { (breathing apparatus). Product does not allow for local adaptations. }\end{array}$ \\
\hline Company I & precision instruments & 2.3 & $\begin{array}{l}\text { Product Excellence Center: extensive technology and product development as well as high market } \\
\text { responsibilities. SUB designs and develops new product architectures (e.g. weighing scales) and technologies. It } \\
\text { is responsible for worldwide sales and engages in local sourcing. }\end{array}$ \\
\hline
\end{tabular}

${ }^{\mathrm{a}}$ in billion US dollars as of 2011

${ }^{\mathrm{b}} \mathrm{HQ}$ : headquarters; SUB: subsidiary

Table 3: Overview of coordination mechanisms in the headquarters-subsidiary relationship 


\section{Case}

\section{Formal coordination mechanisms}

Company A

HQ decide about product strategy, architecture, and development activities. HQ prescribe R\&D tasks for SUB and permanently control the SUB's project progress. HQ and SUB R\&D managers personally meet at least two times per month

Company B HQ decide about product architecture and own systems engineering competence. HQ provide detailed performance requirements and SUB progress is constantly controlled. Head of R\&D or delegates visit subsidiary every two months.

Company C HQ decide about product architecture but SUB has subsystem development responsibilities. HQ and SUB managers frequently exchange personally and virtually. HQ has implemented common development processes at HQ and SUB location.

Company D HQ define product architecture and systems interaction but SUB has module responsibilities. HQ has implemented common development processes at HQ and SUB location. SUB's progress in module development is constantly controlled.

Company E HQ own system engineering competences and defines overall product architecture while SUB is responsible for the development of a specific subsystem. HQ and SUB have frequent planned and unplanned meetings per month. HQ and SUB have shared development processes regarding system interfaces.

Company F Frequent top management meetings. Otherwise there is little formal coordination as SUB has entire product and market responsibility. HQ

\section{Informal coordination mechanisms}

Virtually no informal coordination.

Hybrid coordination mechanisms

Modular product architecture and clearly

defined technical parameters of the module interface enable self-contained and independent work at the SUB. SUB knows which technical parameters to adhere to.

Virtually no informal coordination.

HQ and SUB share a profound understanding of product architecture and the interplay

between subsystems. Common understanding of the overall product requirements, performance, and future technical developments. Physical and virtual communication during subsystem integration.

Frequent informal communications. Common understanding between the HQ and the SUB about the product and local market strategy and about how localization is most efficiently achieved.

Well established common understanding of the product architecture enabled by a system engineering team consisting of HQ and SUB engineers. This also leads to frequent informal exchange. Physical and virtual communication during subsystem integration.

Common vision of product strategy and frequent physical and virtual exchange between engineers for knowledge transfer
High product modularity with pre-defined software parameters and performance requirements enables self-contained and independent module development at the SUB Use of promoter between HQ and SUB.

High product modularity with clearly defined subsystem interfaces enables self-contained and independent subsystem development at the SUB.

Clearly defined module interfaces and modular product architecture enable selfcontained and independent work at the SUB: SUB knows range and requirements of modules which it is free to adapt

Product architecture is very modular and serves as development framework for all subsidiaries. Clearly defined subsystem interfaces enable independent subsystem development activities at SUB

SUB develops entire products which are based on a shared technology platform. This serves as common anchor point between HQ and 
Case

\section{Formal coordination mechanisms}

serve as advisor.

Company G HQ define product architecture, systems, and modules interaction while SUB has component development responsibilities. HQ monitor SUB's development activities.

Company H HQ decide about product strategy and systems interaction while SUB is responsible for all subsystem development. HQ and SUB follow the same development process guidelines. HQ and SUB engineers meet frequently both personally and virtually.

Company I HQ maintain corporate R\&D support while SUB is completely responsible for definition and development of product architecture as well as worldwide sales. HQ and SUB managers frequently meet personally and virtually.
Informal coordination mechanisms

\section{during product development.}

Frequent mutual visits of engineers during component development activities. Two times per year joint workshop for socializing and to transfer latest knowledge.

Common understanding of product architecture and requirements and regular rotation of HQ and SUB engineers. Once per year meeting where all subsidiaries gather and present their development activities and technical competences. Physical and virtual communication during subsystem integration

HQ and SUB have two times per year product strategy meeting which reinforces common understanding of the entire product. HQ supports SUB on demand with technical know-how and development capacities. Frequent informal physical and virtual exchange for knowledge transfer during product development and for global product portfolio integration
Hybrid coordination mechanisms

SUB. Occasionally, task forces are employed to develop market strategies.

Modular product architecture enables selfcontained and independent work at the SUB:

SUB knows range of features which it is free to adapt. Occasionally, a temporary development team consisting of HQ and SUB engineers is assembled to develop urgent technical solutions for specific markets.

Clearly defined product architecture with subsystem interfaces enables self-contained and independent work at the SUB. Interfaces serve as orientation guideline.

HQ has know-how about core systems of the product. This serves as anchor point during technical interactions between HQ and SUB. On demand, cross-site engineering teams are employed and lead by HQ which support other SUBs in specific development activities.

${ }^{\mathrm{a}}$ EWB=Extended Workbench; LA=Local Adaptor; TEC=Technology Excellence Center; PEC=Product Excellence Center; HQ=Headquarters; SUB=Subsidiary 
Figure 1: R\&D subsidiary typology based on technology and market orientation.

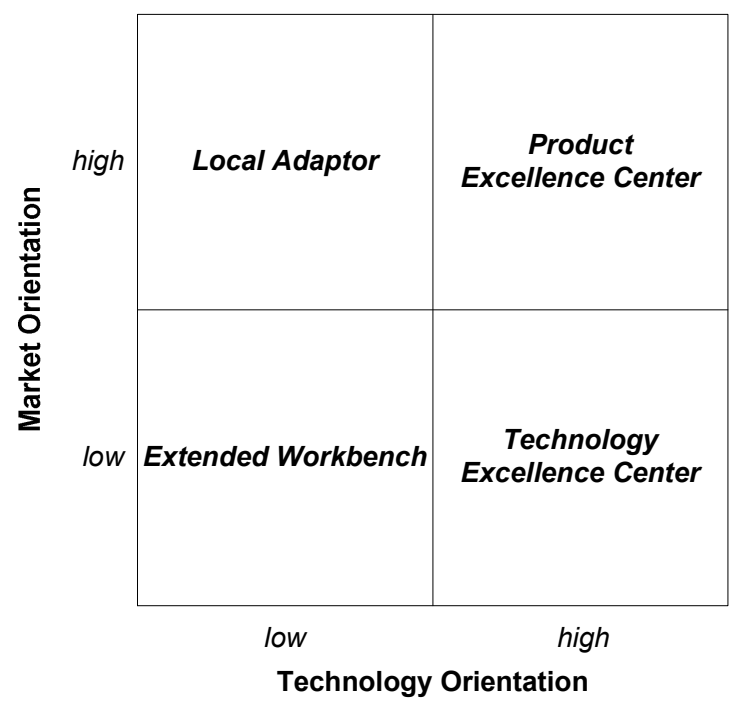

Figure 2: Subsidiary mandate as determined by technology and market orientation.

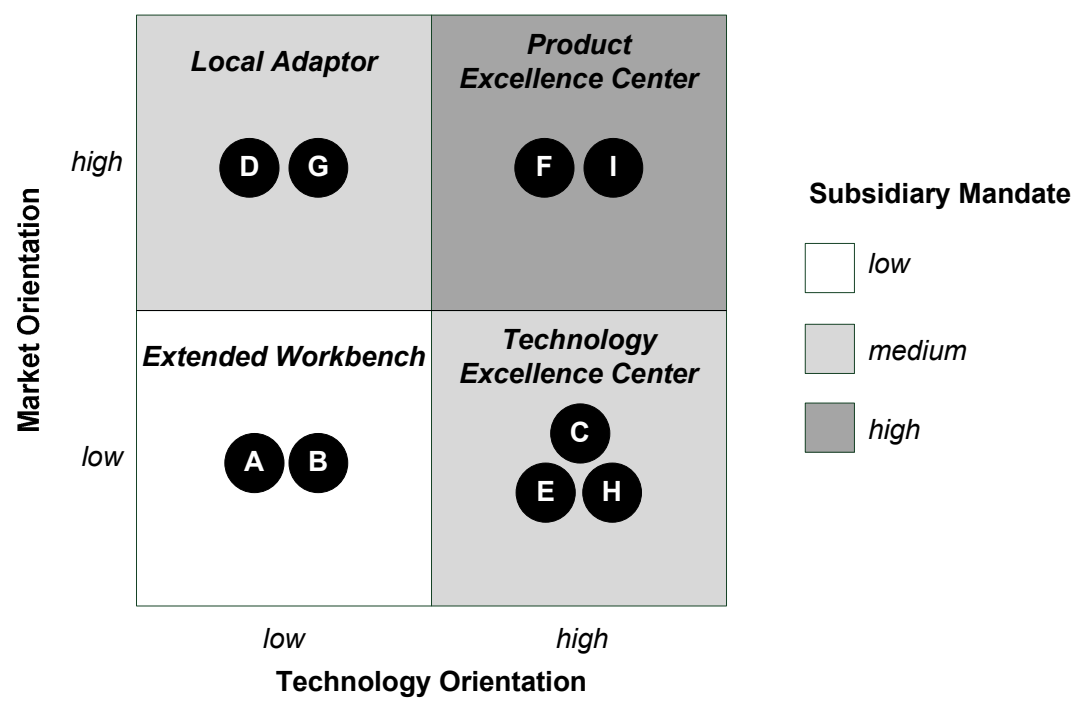


Figure 3: Coordination efforts as a function of technology and market orientation.

\section{Coordination Effort}

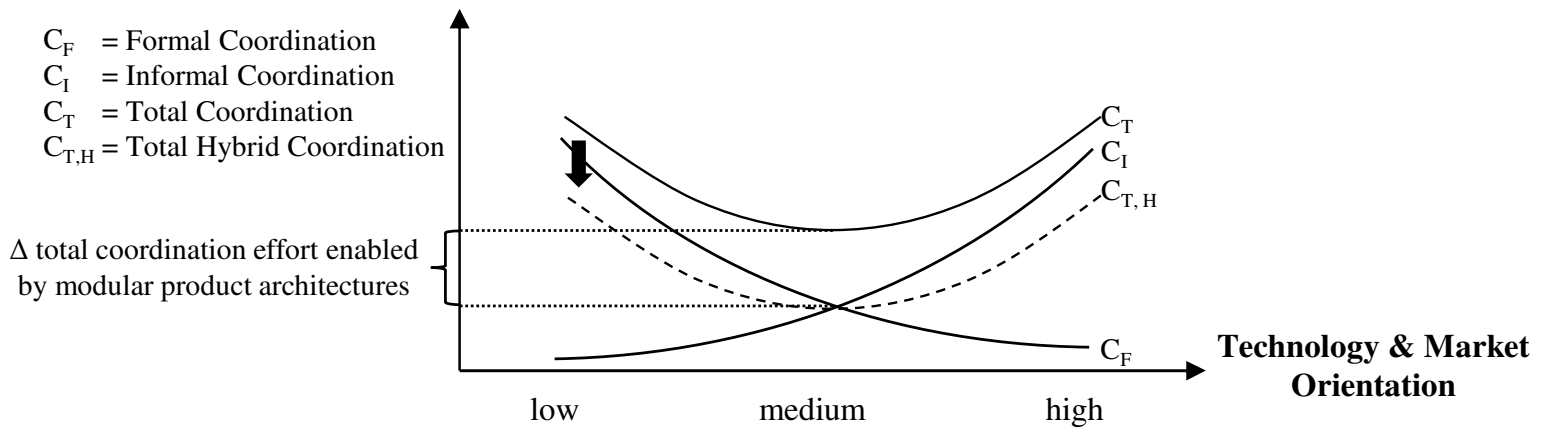

